\title{
Sex and tissue specific gene expression patterns identified following de novo transcriptomic analysis of the Norway lobster, Nephrops norvegicus
}

Guiomar Rotllant ${ }^{*^{*}}$, Tuan Viet Nguyen ${ }^{2^{*} \dagger}$, Valerio Sbragaglia ${ }^{1,3}$, Lifat Rahi ${ }^{4}$, Kevin J. Dudley $^{4}$, David Hurwood ${ }^{4}$, Tomer Ventura ${ }^{2}$, Joan B. Company ${ }^{1}$, Vincent Chand ${ }^{4}$, Jacopo Aguzzi ${ }^{1}$ and Peter B. Mather ${ }^{4}$

\begin{abstract}
Background: The Norway lobster, Nephrops norvegicus, is economically important in European fisheries and is a key organism in local marine ecosystems. Despite multi-faceted scientific interest in this species, our current knowledge of genetic resources in this species remains very limited. Here, we generated a reference de novo transcriptome for $N$. norvegicus from multiple tissues in both sexes. Bioinformatic analyses were conducted to detect transcripts that were expressed exclusively in either males or females. Patterns were validated via RT-PCR.

Results: Sixteen $N$. norvegicus libraries were sequenced from immature and mature ovary, testis and vas deferens (including the masculinizing androgenic gland). In addition, eyestalk, brain, thoracic ganglia and hepatopancreas tissues were screened in males and both immature and mature females. RNA-Sequencing resulted in $>600$ million reads. De novo assembly that combined the current dataset with two previously published libraries from eyestalk tissue, yielded a reference transcriptome of 333,225 transcripts with an average size of 708 base pairs (bp), with an N50 of $1272 \mathrm{bp}$. Sex-specific transcripts were detected primarily in gonads followed by hepatopancreas, brain, thoracic ganglia, and eyestalk, respectively. Candidate transcripts that were expressed exclusively either in males or females were highlighted and the 10 most abundant ones were validated via RT-PCR. Among the most highly expressed genes were Serine threonine protein kinase in testis and Vitellogenin in female hepatopancreas. These results align closely with gene annotation results. Moreover, a differential expression heatmap showed that the majority of differentially expressed transcripts were identified in gonad and eyestalk tissues. Results indicate that sex-specific gene expression patterns in Norway lobster are controlled by differences in gene regulation pattern between males and females in somatic tissues.

(Continued on next page)
\end{abstract}

\footnotetext{
* Correspondence: guio@icm.csic.es; tnguyen@usc.edu.au

${ }^{\dagger}$ Equal contributors

${ }^{1}$ Institut de Ciències del Mar (CSIC), Passeig Marítim de la Barceloneta, 37-49,

08003 Barcelona, Spain

${ }^{2}$ Faculty of Science, Health, Education and Engineering, GeneCology

Research Centre, University of the Sunshine Coast, Sunshine Coast, QLD,

Australia

Full list of author information is available at the end of the article
}

(c) The Author(s). 2017 Open Access This article is distributed under the terms of the Creative Commons Attribution 4.0 International License (http://creativecommons.org/licenses/by/4.0/), which permits unrestricted use, distribution, and reproduction in any medium, provided you give appropriate credit to the original author(s) and the source, provide a link to the Creative Commons license, and indicate if changes were made. The Creative Commons Public Domain Dedication waiver (http://creativecommons.org/publicdomain/zero/1.0/) applies to the data made available in this article, unless otherwise stated. 
(Continued from previous page)

Conclusions: The current study presents the first multi-tissue reference transcriptome for the Norway lobster that can be applied to future biological, wild restocking and fisheries studies. Sex-specific markers were mainly expressed in males implying that males may experience stronger selection than females. It is apparent that differential expression is due to sex-specific gene regulatory pathways that are present in somatic tissues and not from effects of genes located on heterogametic sex chromosomes. The $N$. norvegicus data provide a foundation for future gene-based reproductive studies.

Keywords: Norway lobster, Nephrops norvegicus, Gene expression, Reproduction, RNA-Seq, Sex-specific expression, Sex-biased expression, Transcriptome

\section{Background}

As with many other commercially important aquatic species, a global decline has been reported for the Norway lobster, Nephrops norvegicus in recent years. According to the Food and Agriculture Organization (FAO), N. norvegicus captures declined from $75,999 \mathrm{t}$ in 2007 to $54,762 \mathrm{t}$ by 2014 [1]. A general decline in decapod crustacean fisheries around the world has been attributed to a diverse array of factors. Major drivers contributing to the steady decline in wild crustacean populations include: inadequate legislation for management of wild resources, high fishing quotas, decreases in individual sizes of the crustacean species targeted, and a general increase in worldwide demand for crustaceans [2]. In order to implement well-informed management plans for key harvested species, we need to develop a clear understanding of critical factors that influence wild population health and persistence. Factors range from understanding each species' ecology through to individual physiological characteristics as well as understanding the molecular basis of the natural reproductive biology of each species. As an example, at the ecological level, understanding habitat preferences of key species can inform managers about the potential benefits of marine reserves, their minimum dimensions and boundaries. At the physiological level, understanding annual patterns of growth and reproduction can better inform fishing quota limits based on gender, size and season. At the molecular level, understanding natural reproductive cycles can assist development and implementation of wild restocking programs or potentially development of breeding programs that focus on single sex cohorts. As a recent example, farming of giant freshwater prawn (Macrobrachium rosenbergii) has been enhanced via molecular manipulation of sex so that either all-male or all-female populations can now be practiced. This development required molecular characterization of genetic sex markers [3], in addition to gene silencing of the Androgenic gland insulin-like hormone (IAG) in order to generate all-male populations [4], or introduction of androgenic gland cells to generate all-female populations [5]. Application of these molecular approaches to other farmed decapod crustacean species has yet to be validated.
Most decapod crustaceans studied to date are dioecious, sexually dimorphic and start to differentiate into their individual genetic sexes as larvae [6]. Current knowledge about the molecular pathways involved in regulating the processes of sex determination and sexual differentiation in decapod crustaceans has been reviewed only recently [7]. In brief, initiation of sexual development occurs via a sex-specific genetic cascade mediated via a chromosomal process of sex determination. Chromosomal mechanisms are not conserved and can include either homogametic (ZZ/ZW) or heterogametic $(\mathrm{XY} / \mathrm{XX})$ males. A number of sex determination-linked factors have been identified previously in some decapods including the master Sex-determinant in Drosophila (Sxl) and downstream mediators that include Transformer (TRA) 1 and TRA-2 as well as Feminizer-1 (FEM-1). Identification of decapod copies of these genes were based on homology with sequences identified and characterized in the nematode Caenorhabditis elegans and arthropod model organisms. What is clear is that the sex determination pathway in decapods is far from being conserved and must have evolved independently numerous times. This makes it very difficult to trace master regulators in non-model organisms. In this sense, pursuit of evolutionarily potentially conserved key genes like Double-sex and mab-3 related transcription factor Dmrt could prove useful [8].

After genetic sex has been determined, a complex process of sexual differentiation follows, resulting in sexspecific phenotypic development. The effect of the malespecific androgenic gland (AG) is fundamental to male sexual differentiation. The AG is located close to the sperm duct or testis and is responsible for expression of insulin-like hormone that controls testicular development directly right through to emergence of male secondary-sexual characteristics. It also influences sexual behavior. The AG itself is regulated by the primary neuroendocrine center referred to as the $\mathrm{X}$-organ-Sinusgland complex (XO-SG) that is located in the eyestalk. XO-SG acts through the XO-SG - AG - Gonad axis and secretes a multitude of neurohormones including gonad/vitellogenesis inhibiting hormone (GIH/VIH) and 
molt-inhibiting hormone (MIH). GIH/VIH and $\mathrm{MIH}$ are believed to regulate IAG expression directly and have an ongoing inhibitory effect during sexual development and during reproduction. XO-SG secreted neurohormones also control sexual maturation that enable reproductive functionality in concert with additional regulatory factors (either peptides or neuromodulators) produced in the brain and thoracic ganglia (TG). Together they regulate secrete two lipid factors: i) the molt hormone ecdysone and ii) the metamorphosis-regulating hormone methyl farnesoate (MF) that are produced by the Y-organ and the mandibular organ, respectively [9]. The two factors are considered to have conserved key roles during arthropod gonadal maturation [10]. It is becoming clear however, that there are additional unknown regulatory genes and pathways (yet to be identified) involved in the process. Further investigation will be required therefore, to better understand the complete molecular basis for biological differences between male and female crustaceans in addition to resolving intricate sexual developmental pathways.

The Norway lobster constitutes one of the most important fisheries in European waters while being the most valuable harvested crustacean across the region. This species is closely monitored by the International Council for the Exploration of the Sea (ICES) under the Working Group on Nephrops Surveys http://www.ices.dk/community/groups/Pages/WGNEPS.aspx. Given perceived threats from over-exploitation and also its relative importance in regional fisheries, $N$. norvegicus biology, including reproduction, has been reviewed several times over recent decades [11-14]. In brief, $N$. norvegicus has a wide distribution in European waters, including both shallow and deep waters in the Atlantic Ocean and Mediterranean Sea. Despite an extensive natural distribution (or perhaps as a function thereof, i.e. there is no biogeographical barrier to inhibit inshore/offshore connectivity), no inter-populational genetic differentiation has been detected to date at any geographical scale examined. $N$. norvegicus is a decapod in the suborder Pleocyemata a group that is characterized by females carry eggs on their abdomen after fertilization from sperm deposited previously by a male during copulation and then stored in the female's thelycum until spawning takes place. Females carry eggs on their abdomen for a period that varies between 6 (Mediterranean Sea) to 11 months (Iceland) after which embryos hatch and undergo larval development that involves three planktonic larval stages and a single benthic postlarval stage that lasts on average one month depending on water temperature. Reproduction as a consequence, takes place biannually (Iceland) or annually (Mediterranean Sea). Males and females are morphologically similar apart from their secondary sexual characteristics (i.e. claw allometry and presence of a petasma in males, and thelycum in females). Anatomy of the reproductive system in $N$. norvegicus has been described in detail for both males [15] and females [16].

Apart from a vast knowledge about the physiology of $N$. norvegicus reproduction, there is a major gap with respect to our understanding of the molecular mechanisms underlying regulation of reproduction. Recent advances in genomics technologies can help to fill this gap. The number of studies that have used nextgeneration sequencing technology (NGST) and microarrays on crustacean taxa has increased significantly in recent years. As examples, studies have been conducted recently on freshwater crayfish Astacus astacus [17], Cherax cainii [18], Cherax destructor [18], Cherax quadricarinatus [19-21], Pontastacus leptodactylus [22], Procambarus clarkii [23-26] and clawed lobsters Homarus americanus [27-30] and N. norvegicus [31], all members of the infraorder Astacidea. In this last study, two transcriptomes were published from eyestalk tissues from adult males maintained in a laboratory under dark or light conditions. Here, we generated a multi-tissue transcriptome from adult males, and mature and immature females to generate a reference library for the target species that will enhance a depauperate molecular toolkit for future studies directed at better resolving N. norvegicus physiology, development and reproduction.

Earlier studies of sex-biased transcriptomes of crustaceans have focused mainly on adult gonadal tissue, and reported several sex-specific transcripts including; an Ovarian serine protease/nudel homolog in the ovaries of the shrimp Marsupenaeus japonicus [32]; Female sterile and Ovarian lipoprotein receptor homologues in giant tiger shrimp Penaeus monodon [33], as well as Dmrt in the Chinese mitten crab Eriocheir sinensis [34]. A sexbiased gene expression analysis has also been conducted on whole individual samples of juvenile E. sinensis [35]. The authors classified 40 unigenes as testis or spermspecific genes and 24 as ovary or oocyte-specific genes. Of the sex-biased genes identified in the juvenile transcriptomes, the study validated and showed that Nit protein 2-like (NIT2) was highly up-regulated in females and CYP3A4 (Cytochrome P450, family 3, subfamily A, polypeptide 4) was up-regulated in males. Gao et al. [36] also validated 33 ovary-specific expressed transcripts and 14 testis-specific expressed transcripts, but the genes were not annotated.

The present study is the first relating to sex-specific transcripts in crustaceans that can lead to discovery of genomic-based sex markers with potential to shed new light on sex determination mechanisms. Here we screened five tissues (gonads, eyestalks, thoracic ganglia, brain and hepatopancreas) that target the most relevant genes involved with reproduction and in particular, sex- 
specific gene expression in $N$. norvegicus. The multitissue reference libraries from males, immature and mature females developed here will increase our knowledge about regulation of reproductive pathways and contribute greatly to planned future gene-based studies. Ultimately, these factors are likely to be of utmost importance when developing appropriate fisheries management tools that allow ongoing sustainable exploitation of wild $N$. norvegicus stocks.

\section{Methods}

\section{Sampling and RNA extraction}

Adult $N$. norvegicus were collected offshore from Barcelona harbour (Spain) from the trawling fishing vessel Maireta III. On board, male and female $N$. norvegicus were separated based on previously described external sexual characteristics [11]. Females were further separated into mature (stage IV) and immature (stage II) females, as previously described [16]. Tissues (testes, vas deferens, ovaries, hepatopancreas, muscle, eyestalks, brain and thoracic ganglia) were then dissected out and samples preserved in RNA-later (Ambion) and stored at $-80{ }^{\circ} \mathrm{C}$ for later use. Samples were transported to the Molecular Genetics Research Facility at the Queensland University of Technology (Australia) for total RNA extraction, cDNA libraries synthesis, sequencing and downstream bioinformatics analyses., Samples of each tissue from 3 to 4 individuals were pooled to create a master pool. Total RNA was extracted using a modified TRIsure ${ }^{\mathrm{mm}}$ (Bioline, AU) protocol according to the manufacturer's recommendations. Total RNA purity as well as concentration were checked using a spectrophotometer (Beckman Coulter) and Qubit RNA Assay Kit on the Qubit 2.0 Fluorometer (Life Technologies, USA). RNA integrity was evaluated using an Agilent Bioanalyzer 2100 (Agilent Technologies, CA, USA).

\section{Preparation of cDNA libraries and Illumina sequencing}

Sequencing libraries were generated using Illumina TruSeq Stranded mRNA Sample Preparation Kit (Illumina Inc., CA, USA) following the manufacturer's recommendations. In brief, poly-T-oligo magnetic beads supplied in the kit were used to capture mRNA from total RNA. Fragmentation was then carried out using divalent cations, followed by reverse transcription into first strand cDNA using reverse transcriptase and random primers. A second strand of cDNA was then synthesized using DNA polymerase I and RNAse. All products were further purified and amplified via PCR to generate the pre-sequencing cDNA libraries. Finally, all libraries preparations were sequenced on the Illumina NextSeq 500, resulting in the final 150 bp paired-end (PE) reads used in the study.

\section{Quality control and de novo assembly of the reference transcriptome}

Reads output from Illumina NextSeq in the form of FASTQ files were stored, backed up and assessed for quality using FastQC software [37]. Reads from the current dataset were merged with additional Illumina reads from a previous study (two eyestalk libraries adult male lobsters kept in captivity for six months were sampled at night and during the day) [31]. The bioinformatics workflow employed here is illustrated in Fig. 1. Quality assurance of reads was conducted using Trimmomatic [38]. The software was designed specifically for Illumina reads to identify and trim nucleotides falling below a pre-set threshold. The parameters used in the current study were LEADING $=5$; TRAILING $=5$; SLIDINGWINDOW = 3:10; MINLEN = 26; HEADCROP $=8$. After trimming, all cDNA libraries were reassessed again for quality metrics (data not shown). All post quality control FASTQ files were then concatenated and de novo assembled using Trinity [39] on the Lyra HPC at Queensland University of Technology. Trinity was run on filtered PE reads applying a fixed k-mer value of 25 , min_kmer_cov 2 and minimum contig length of $200 \mathrm{bp}$. The output FASTA file (the final reference transcriptome) was then tested for post-assembly metrics including N50 and total number and contig length. The final reference transcriptome was assessed for completeness using CEGMA (Core Eukaryotic Genes Mapping Approach) [40].

\section{Functional annotation of the reference transcriptome}

All assembled contigs were scanned against the NCBI non-redundant database (nr) using BlastX algorithm with E-value threshold set at 1.00E-6. Blasted contigs were then loaded into BLAST2GO version 3.0 [41], an automated toolset used for characterizing large datasets for Gene Ontology (GO) annotation. Annotated transcripts were distributed into three ontology categories: molecular function, cellular component and biological process. A final annotation file was produced after GO-mapping, GO term assignment, annotation augmentation and a generic GO-Slim process. After obtaining GO annotation, Web Gene Ontology Annotation Plot (WEGO) software [42] was used to characterize the distribution of gene functions from the generated reference transcriptome.

\section{Mapping, reads counting and sex-specific transcripts evaluation}

Trimmed reads from gonad, hepatopancreas, eyestalk, brain and thoracic ganglia dissected from wild caught mature males and mature females (not including the laboratory reared males and immature females) were mapped back to the reference transcriptome assembly 


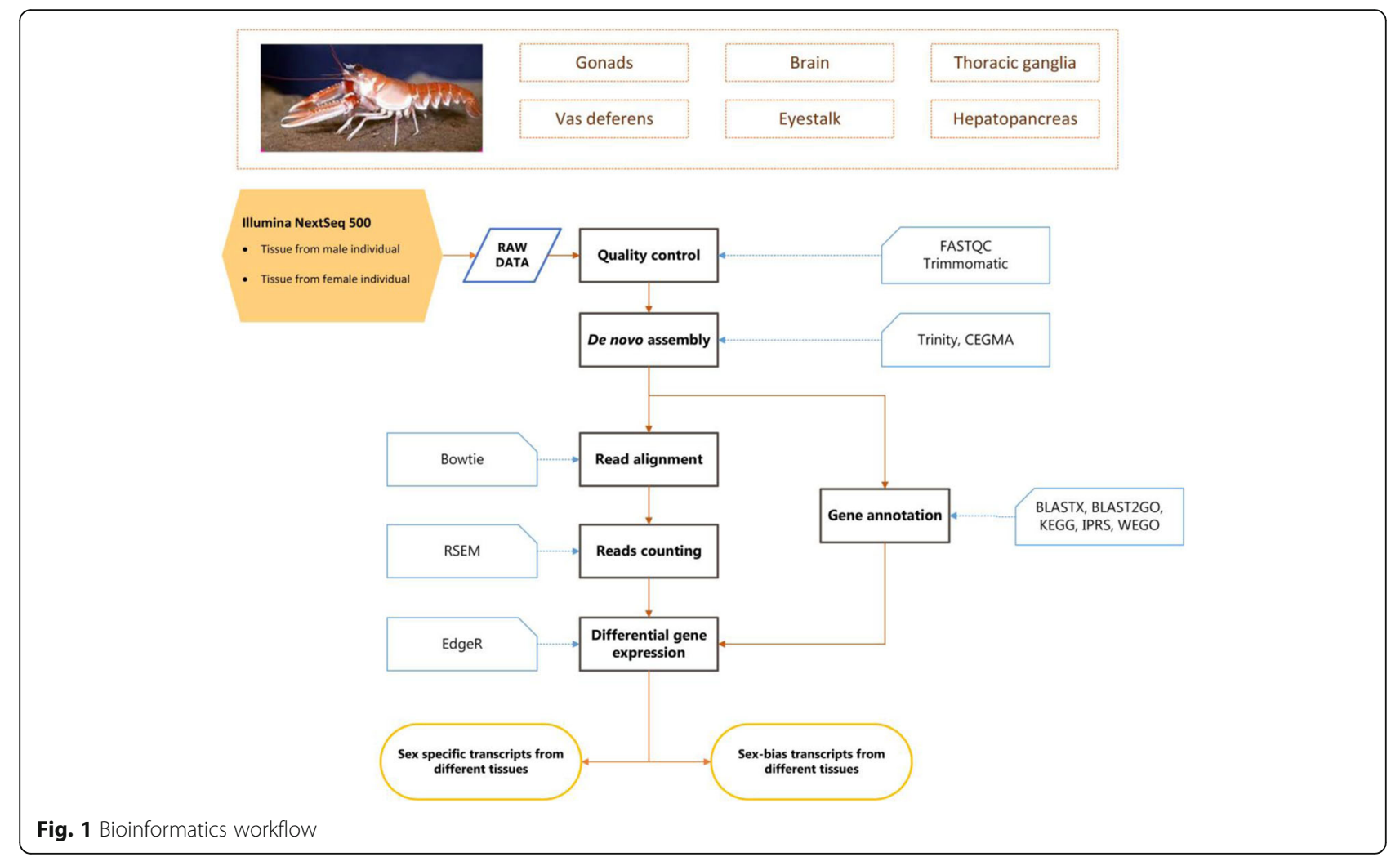

using Bowtie applying default settings [43]. Read counts were generated using RSEM [44]. EdgeR software [45] was used to conduct differential gene expression analysis and to calculate false discovery rate of multiplehypothesis testing. The following data filtering were used: $p$-value $<0.001$, FDR (false discovery rate) value $<0.001$ and at least 200 reads in either male or female. From the filtered data, a transcript to be considered as a sex-specific candidate had to have a read count of 0 in either male or female. To select for the most representative genes we chose the 30 most abundant transcripts from each sex and tissue.

\section{RT-PCR confirmation of sex-specific transcripts}

Among abundantly-expressed sex-specific transcripts, we selected five per sex based on previous reports and GO annotation. We also selected a random transcript per sex from the 20 most abundant sex-specific transcripts. We tested the sex-specific transcripts using Reverse Transcriptase PCRs (RT-PCR) to amplify the cDNA product, followed by PCR using genomic DNA (gDNA) as a template.

\section{$R T-P C R$}

We used 3 samples from both males and females with each sample comprising a pool of tissue from 3 to 4 animals. RNA was extracted using the method described above. Selected tissues were gonads for all genes tested
(Serine threonine protein kinase, STPK; Venom c-type lectin mannose binding, CTL; Meprin, MEP; Slowpoke potassium channel family, SLO; Dual specificity mitogenactivated protein kinase, MAPK; Mannose-binding protein, MBP; Von Willebrand factor, VWF; Vitellogenin receptor, VgR; Meloxyperoxidase, MPO) and hepatopancreas for Vitellogenin, Vg. As housekeeping (internal reference) genes, we used Elongation factor $1 \boldsymbol{\alpha}$

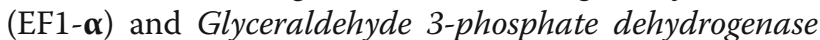
(GAPDH) since they have been validated previously in crustaceans $[46,47]$. Specific primers for each gene were designed using Primer3 software (Additional file 1: Table S1) [48]. In the case of genes with multiple transcripts, all transcripts were aligned to find the common region. Primers were then designed based on the common region to enable amplification of all potential isoforms. Prior to RT-PCR, residual DNA was removed from the RNA using the RQ1 RNase-Free DNase PROMEGA kit (Cat. \# M6101). Then SensiFAST cDNA Synthesis Kit (BIOLINE; Cat. \# BIO-65054) was used for reverse transcription, followed by PCR amplification with MyTaq HS DNA Polymerase (Cat. \# BIO-21112). PCR settings were $95{ }^{\circ} \mathrm{C}$ for $1 \mathrm{~min}$, followed by 30 cycles of $95{ }^{\circ} \mathrm{C}$ denaturation for $15 \mathrm{~s}$, annealing temperature of $56{ }^{\circ} \mathrm{C}$ for $15 \mathrm{~s}$ and extension of $72{ }^{\circ} \mathrm{C}$ for 10s. Following PCR, products were loaded onto an agarose gel $(1.5 \%$ agarose in TrisBorate-EDTA buffer) with GelRed (Cat. \# Biotium$41,003)$ and visualized under UV-light. 


\section{gDNA-PCR}

Extraction of DNA from muscle tissue (3 samples from males and 3 samples from females - each sample represents muscle from a single animal) was conducted using the BIOLINE Isolate II genomic DNA kit (Cat. \# BIO52066). PCR settings were as described above for cDNA.

\section{PCR product sequencing}

To validate amplification of each sex-specific gene, we sequenced PCR products to confirm that their sequence matched the sequence extracted from the transcriptomes. Amplicons were cleaned using Isolate II PCR and gel clean kits (BIOLINE; Cat. \# BIO-52059) and then sequenced on an ABI 3500 Genetic Analyzer (Applied Biosystems, CA, USA). Geneious software v8.1 (Biomatters Ltd., New Zealand) was utilized for sequence analyses.

\section{Differential gene expression and sex-biased transcript evaluation}

Previously performed mapping, read counting and differential gene expression (DGE) analyses (described above) served for sex-biased transcript analysis. The designated threshold for any transcript to be considered as significantly different between male and female was $\mid \log$ (Fold change) $\mid>2$, $p$-value $<0.001$, FDR value $<0.001$. Heatmaps showing clusters of transcripts that were different between sexes for each tissue were illustrated using the analyse_diff_expr.pl scripts included in the Trinity de novo assembler [39]. Data were log2-transformed for the illustration and with an E-value threshold set at 1.00E-6. Two dimensional plots of principal components were calculated by performing principal component analysis (PCA) of the transposed log2-transformed FPKM values from male and female eyestalk, brain and thoracic ganglia samples using $\mathrm{R}$ software.

\section{Results}

Generation of a Nephrops norvegicus reference library

In total, our libraries resulted in more than 600 million reads from the Illumina NextSeq 500. That, combined with the previously generated Hiseq 2000 libraries, provided more than 800 million reads. On average, each library had more than 50 million reads with $>90 \%$ of reads above the quality threshold for all libraries. All raw reads and quality control statistics are presented in Table 1.

De novo transcriptome assembly of the current dataset using the Trinity assembler generated 333,225 transcripts, with an average transcript size of 708 base pairs (bp) and N50 of $1272 \mathrm{bp}$. Total size of the reference transcriptome was $235,992,830 \mathrm{bp}$. All transcripts were longer than $200 \mathrm{bp}$ and we recorded more than 51,000 transcripts longer than $1000 \mathrm{bp}$. To assess the completeness of transcriptome assembly, we employed CEGMA packages resulting in $97.53 \%$ completeness, indicating

Table 1 Raw reads and quality control of reads for N. norvegicus libraries

\begin{tabular}{|c|c|c|c|c|c|c|}
\hline Tissue & Sex & $\begin{array}{l}\text { Number of raw } \\
\text { reads }\end{array}$ & $\begin{array}{l}\text { Raw read } \\
\text { length }\end{array}$ & $\% G C$ & $\begin{array}{l}\text { Number of reads } \\
\text { after trimming }\end{array}$ & $\begin{array}{l}\text { Read length } \\
\text { after trimming }\end{array}$ \\
\hline Testis & M & $47,454,625$ & 151 & 44 & $44,384,279$ & $26-143$ \\
\hline \multirow[t]{2}{*}{ Ovary } & MF & $56,859,898$ & 151 & 43 & $53,448,056$ & $26-143$ \\
\hline & IF & $52,854,378$ & 151 & 48 & $49,655,513$ & $26-143$ \\
\hline Vas Deferens & M & $49,222,546$ & 151 & 43 & $46,802,691$ & $26-143$ \\
\hline \multirow[t]{3}{*}{ Hepatopancreas } & M & $56,240,204$ & 151 & 43 & $52,803,977$ & $26-143$ \\
\hline & MF & $54,715,141$ & 151 & 46 & $50,574,033$ & $26-143$ \\
\hline & IF & $52,217,561$ & 151 & 46 & $48,752,848$ & $26-143$ \\
\hline \multirow[t]{3}{*}{ Eyestalk } & M & $44,910,345$ & 151 & 43 & $41,968,679$ & $26-143$ \\
\hline & MF & $45,799,203$ & 151 & 42 & $42,121,851$ & $26-143$ \\
\hline & IF & $53,668,850$ & 151 & 42 & $49,410,048$ & $26-143$ \\
\hline \multirow[t]{3}{*}{ Brain } & M & $58,405,643$ & 151 & 42 & $54,423,042$ & $26-143$ \\
\hline & MF & $67,530,741$ & 151 & 42 & $62,997,606$ & $26-143$ \\
\hline & IF & $61,357,339$ & 151 & 42 & $57,343,088$ & $26-143$ \\
\hline \multirow[t]{3}{*}{ Thoracic ganglia } & M & $47,227,119$ & 151 & 41 & $43,723,658$ & $26-143$ \\
\hline & MF & $58,418,219$ & 151 & 43 & $54,460,212$ & $26-143$ \\
\hline & IF & $49,303,270$ & 151 & 42 & $45,710,029$ & $26-143$ \\
\hline \multicolumn{7}{|c|}{ Data from a previous study [7] } \\
\hline \multirow[t]{2}{*}{ Eyestalk } & $M L$ & $87,830,082$ & 101 & 41 & $84,425,620$ & $26-89$ \\
\hline & $\mathrm{MD}$ & $91,938,198$ & 101 & 44 & $87,970,542$ & $26-89$ \\
\hline
\end{tabular}

IF immature female; $M$ Male; MD Male maintained in Darkness; MF mature female; $M L$ Male maintained in Light conditions 
the high quality de novo assembly. A brief summary of de novo assembly statistics are provided in Table 2.

Gene identification was conducted after generation of the reference transcriptome, BLAST searches were conducted using the BlastX algorithm against the $\mathrm{Nr}$ (nonredundant protein sequences in NCBI). Only 37,296 transcripts $(11 \%)$ showed significant hits against known proteins. Of these, only 20,595 (6\%) transcripts could be fully annotated with $\mathrm{GO}$ available data, illustrating the scarcity of crustacean sequences in current genomic databases. The most abundant BLAST hits were associated with a widely studied crustacean species Daphnia pulex (9\%), and then several insect species Tribolium castaneum (6\%), Pediculus humanus (4\%), Strongylocentrotus purpuratus (3\%) and Acyrthosiphon pisum (3\%). The highest hits for species distribution were associated with unknown species (48\%) (Additional file 1: Table S1).

We also generated a GO annotation plot to visualize the distribution of GO terms in our reference transcriptome. The percentages of annotated $N$. norvegicus sequences assigned to GO terms are shown in Fig. 2. Analysis of GO term distribution showed that cell (GO:0005623), binding (GO:0005488) and cellular process (GO:0009987) were the most common annotation terms within the three GO categories.

\section{Sex-specific transcripts analyses}

In the current study, we detected a large number of transcripts specifically expressed in male but not in female tissues (and vice-versa; Additional file 1: Table S1). In total, the number of sex-specific transcripts (malespecific numbers / female-specific) were $344 / 111$ in the gonads, $36 / 35$ in the hepatopancreas, $35 / 33$ in the brain, $34 / 14$ in the thoracic ganglia, and finally $22 / 3$ in the eyestalk. Sex-specific transcripts in each tissue are presented in Fig. 3 showing that males always had a higher number of transcripts expressed exclusively compared with females.

The most abundant gonad-specific transcripts included Serine threonine protein kinase, Venom c-type lectin mannose binding protein, Dual specificity mitogen-

Table 2 De novo assembly statistics of the N. norvegicus reference transcriptome

\begin{tabular}{ll}
\hline Number of transcripts & 333,225 \\
\hline Total size of transcripts $(\mathrm{nt})$ & $235,992,830$ \\
Longest transcripts (bp) & 33,925 \\
Number of transcripts $>1 \mathrm{k} \mathrm{bp}$ & 51,881 \\
Number of transcripts $>10 \mathrm{k} \mathrm{bp}$ & 394 \\
Mean transcript size (bp) & 708 \\
N50 transcript length (bp) & 1272 \\
Transcriptome Assembly Completeness (\%) & 97.53 \\
\hline
\end{tabular}

activated protein kinase, Meprin protein and Slowpoke potassium channel protein in males; while in females the most abundant gonad-specific transcripts were Mannose-binding protein, Von Willebrand factor, Myeloperoxidase and Vitellogenin receptor. In the hepatopancreas, the main female-specific transcript found was Vitellogenin with eight different isoforms of $\mathrm{Vg}$ identified. Parameters for the entire list of sex-specific transcripts are listed in supplementary material (Additional file 2: Table S2).

The ten most highly differentially expressed transcripts were subjected to additional analyses. Transcript information, including GO classification, is detailed in Table 3. All sex-specific transcripts tested were found to be specific to a single tissue as well. Validation of expression sex-specific transcripts (cDNA) as well as gDNA amplification are presented in Table 4. Expression profiles of the highest expressed validated sex-specific transcripts in $N$. norvegicus (STPK in the male gonads and $\mathrm{Vg}$ in the female hepatopancreas) are illustrated in Fig. 4. cDNA expression of CTL, MEP, SLO and MAPK were validated in testes while VgR, VWF, MBP and MPO were validated as being specific to ovaries (Additional file 3: Fig. S2). House keeping genes (EF1 $\alpha$ and GAPDH) expression was validated in both gonad and hepatopancreas tissues (Additional file 3: Fig. S2). Sanger sequencing of gDNA in muscle tissue confirmed the presence of all sex-specific gene sequences apart from VWF. Failure to amplify VWF may have resulted from presence of associated introns.

\section{Sex-biased gene differential expression analyses}

While the primary aim of the study was to analyze transcripts that were specific to either males or females, a general evaluation of all sex-biased transcripts was generated, providing an overview of the entire suite of differentially expressed transcripts between sexes (including the sex-specific transcripts, Additional file 4: Table S3).

A heatmap illustrating differential expression patterns of transcripts from multiple tissues (Fig. 5) highlights clusters of transcripts with significant differential expression patterns between males and females. As expected, most differentially-expressed transcripts were detected in the gonads of both sexes. When considering the differentially expressed genes presented in isolation (Fig. 5), the male eyestalk expression profile was similar to brain and thoracic ganglia in both males and females, while female eyestalk showed a very different expression profile compared with the remaining nervous system libraries, a result that was also evident in the PCA analysis (Additional file 5: Fig. S3). Hepatopancreas did not show a large number of transcripts differentially expressed between the sexes. 


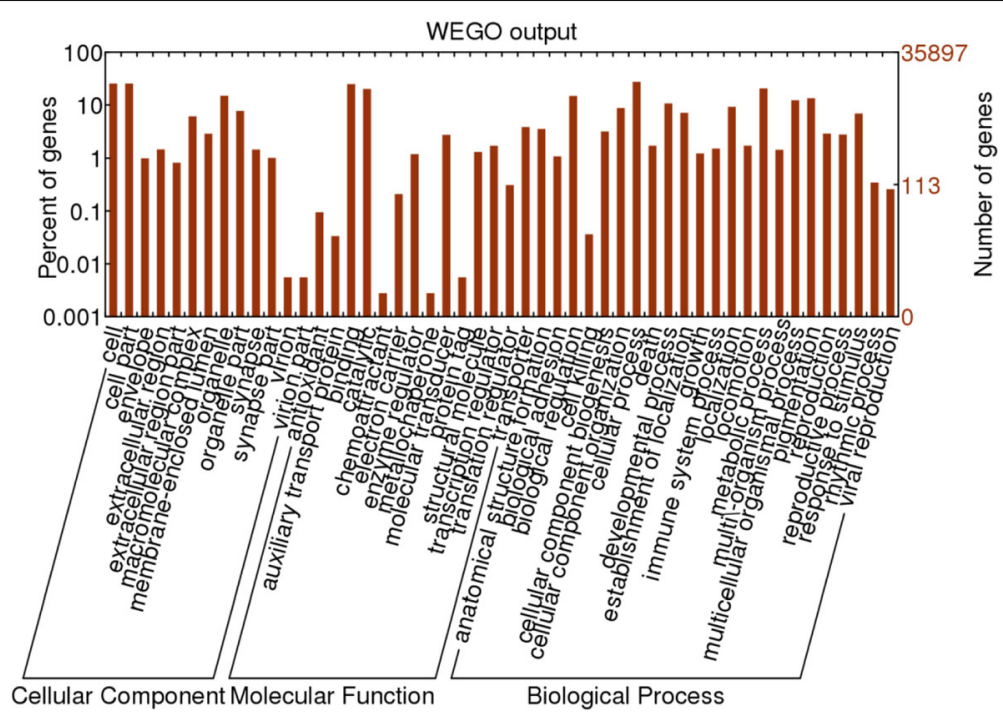

Fig. 2 Distribution of GO terms

\section{Discussion}

A $N$. norvegicus transcriptome was generated to investigate the molecular basis for reproduction in this species but also provides a platform for more general functional genomic studies of Norway lobster. Applications for the transcriptomic data can inform future efforts directed at restocking programs for $N$. norvegicus to support a declining fishery. From an ecological perspective, this transcriptome can also be a valuable resource for assessing differential gene expression patterns as a consequence of natural variation in habitat conditions because $N$. norvegicus possesses a very broad distribution in European waters both in shallow and deep-waters where populations are not structured geographically. The multi-tissue transcriptomic (18 transcriptomes merged from 6 tissues from males and 5 tissues from females) reference library generated here presents a high quality database (N50 of

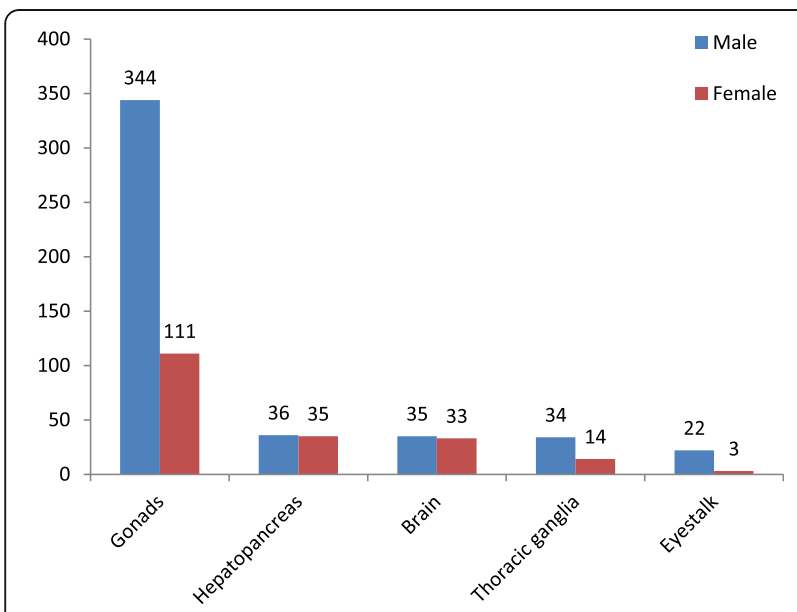

Fig. 3 Comparative sex-specific transcripts among different tissues
$1272 \mathrm{bp}$, average contig length of $708 \mathrm{bp}$ and $97.53 \%$ of CEGMA) allowing deep mining for key factors associated with regulation of reproduction. Assembly numbers are comparable with recent attempts to generate reference transcriptomes for Astacid species [17, 18, 22, 24, 29]. With regard to CEGMA, our results show a slightly higher percentage compared with those for a recently published study of a freshwater decapod, C. quadricarinatus $(94.76 \%)$ but average contig length in our study was shorter [21].

We identified 471 male-specific and 196 femalespecific expressed transcripts in the $N$. norvegicus transcriptome with gonads in both sexes expressing the highest numbers of sex-specific transcripts compared with other sampled tissues. A similar outcome was observed for $M$. japonicus [32]. In addition, the higher number of testis versus ovary up-regulated transcripts found in $N$. norvegicus was a similar result to that obtained for E. chinensis [36], and the Eastern spiny lobster Sagmariasus verreauxi [49]. This implies that female gonadal development may require a smaller number of upregulated transcripts compared with males. This could be due to the effect of male-specific IAG which is known to drive masculinization in crustaceans [7]. If the bias in majority male-specific expression observed for $N$. norvegicus is confirmed, this may result from adaptive changes in males, implying that males may in general, experience stronger selection than females.

Of the 667 transcripts identified in the Norway lobster, 445 were either male or female-specific. From these, we selected ten annotated to sex-related pathways for further validation. Serine threonine protein kinases were found to be highly expressed in the testes of E. sinensis [50]; the authors suggesting that STPKs may play a key 
Table 3 Highly expressed sex-specific transcripts in N. norvegicus

\begin{tabular}{|c|c|c|c|c|c|c|c|}
\hline Sex-specific & Gene & Tissue & Contig \# & \# reads mapped & FPKM & $P$-value & GO annotation \\
\hline \multirow[t]{5}{*}{ Male } & STPK & Testes & c207207_g2_i1 & 123,796 & 7963 & $1.68 \mathrm{E}-37$ & $\begin{array}{l}\text { F: ATP binding; F: protein kinase activity; } P \text { : phosphorylation; } \\
\text { F: protein serine/threonine kinase activity; } P \text { : protein } \\
\text { phosphorylation; F: kinase activity }\end{array}$ \\
\hline & $C T L$ & Testes & c121960_g1_i1 & 20,001 & 1338 & $1.37 \mathrm{E}-29$ & $\begin{array}{l}\text { F: carbohydrate binding; } P \text { : biological_process; } \\
C \text { : cellular_component }\end{array}$ \\
\hline & MEP & Testes & C16959_g1_i2 & 15,261 & 1108 & $2.04 \mathrm{E}-28$ & F: hydrolase activity \\
\hline & SLO & Testes & c158376_g1_i1 & 13,219 & 402 & $8.56 \mathrm{E}-28$ & $\begin{array}{l}\text { F: calcium-activated potassium channel activity; } \\
\text { F: voltage-gated potassium channel activity; } C \text { : membrane; } \\
\text { F: large conductance calcium-activated potassium channel } \\
\text { activity; } P \text { : potassium ion transport; } C \text { : voltage-gated } \\
\text { potassium channel complex; F: metal ion binding; } \\
P \text { : potassium ion transmembrane transport; F: protein } \\
\text { binding }\end{array}$ \\
\hline & MAPK & Testes & c206116_g1_i1 & 15,261 & 1050 & $1.73 \mathrm{E}-29$ & $\begin{array}{l}\text { F: transferase activity, transferring phosphorus-containing } \\
\text { groups }\end{array}$ \\
\hline \multirow[t]{5}{*}{ Female } & $\mathrm{Vg}$ & Hepatopancreas & c208407_g1_i1 & 333,838 & 2843 & $1.36 \mathrm{E}-44$ & $P$ : lipid transport; F: lipid transporter activity; $P$ : oogenesis \\
\hline & MBP & Ovary & c208884_g1_i2 & 5719 & 1075 & $6.26 \mathrm{E}-30$ & F: carbohydrate binding \\
\hline & WWF & Ovary & c207785_g1_i1 & 6210 & 191 & $4.03 \mathrm{E}-28$ & $\begin{array}{l}\text { F: calcium ion binding; } F \text { : metal ion binding; } P \text { : oxidation- } \\
\text { reduction process; F: oxidoreductase activity; } P \text { : metabolic } \\
\text { process; F: chitin binding; } P \text { :chitin metabolic process; } \\
P \text { : cell adhesion; C: extracellular region }\end{array}$ \\
\hline & $\operatorname{VgR}$ & Ovary & c208891_g2_i1 & 2856 & 64 & $9.36 \mathrm{E}-25$ & $\begin{array}{l}\text { F: calcium ion binding; C:integral component of } \\
\text { membrane; C: membrane; F: receptor activity; P: receptor- } \\
\text { mediated endocytosis; } P \text { : endocytosis; } C \text { : cellular_component }\end{array}$ \\
\hline & MPO & Ovary & c179405_g1_i1 & 3761 & 136 & $6.01 \mathrm{E}-26$ & $\begin{array}{l}P \text { : oxidation-reduction process; } F \text { : heme binding; } P \text { : } \\
\text { response to oxidative stress; } F \text { : peroxidase activity }\end{array}$ \\
\hline
\end{tabular}

CTL Venom c-type lectin mannose binding; MAPK Dual specificity mitogen-activated protein kinase; MBP Mannose-binding protein; MEP Meprin; MPO Meloxyperoxidase; SLO Slowpoke potassium channel family; STPK Serine threonine protein kinase; Vg Vitellogenin; VgR Vitellogenin receptor; VWF Von Willebrand factor

Table 4 Expression profile of validated sex genes in N. norvegicus

\begin{tabular}{|c|c|c|c|c|}
\hline \multirow[b]{2}{*}{ GENES } & \multicolumn{2}{|c|}{$\begin{array}{c}\text { mRNA } \\
\text { (gene expression) }\end{array}$} & \multicolumn{2}{|c|}{$\begin{array}{c}\text { gDNA } \\
\text { (amplification) }\end{array}$} \\
\hline & Male & Female & Male & Female \\
\hline Serine threonine protein kinase & + & - & + & + \\
\hline $\begin{array}{l}\text { Venom c-type lectin mannose } \\
\text { binding }\end{array}$ & + & - & + & + \\
\hline Meprin & + & - & + & + \\
\hline Slowpoke potassium channel family & + & - & + & + \\
\hline Mitogen-activated protein kinase & + & - & + & + \\
\hline Vitellogenin & - & + & + & + \\
\hline Mannose-binding protein & - & + & + & + \\
\hline Von Willebrand factor & - & + & - & - \\
\hline Vitellogenin receptor & - & + & + & + \\
\hline Meloxyperoxidase & - & + & + & + \\
\hline Elongation factor $1 \mathrm{a}$ & + & + & * & * \\
\hline $\begin{array}{l}\text { Glyceraldehyde 3-phosphate } \\
\text { dehydrogenase }\end{array}$ & + & + & * & $*$ \\
\hline
\end{tabular}

+: amplified successfully; -: not amplified; *: not applicable role in both mitotic and meiotic divisions and extensive cellular re-modelling through cell cycle phases during spermatogenesis. In $M$. rosenbergii, a male reproductiverelated protein homologous with STPK was found to be expressed exclusively in the sperm ducts as a protein with a putative role in phosphorylation and with a function involved with sperm capacitation and/or fertilization [51]. In $N$. norvegicus, 24 transcripts annotated as STPK were detected exclusively in the testes suggesting that several isoforms could have different functions in male reproduction (Additional file 4: Table S3).

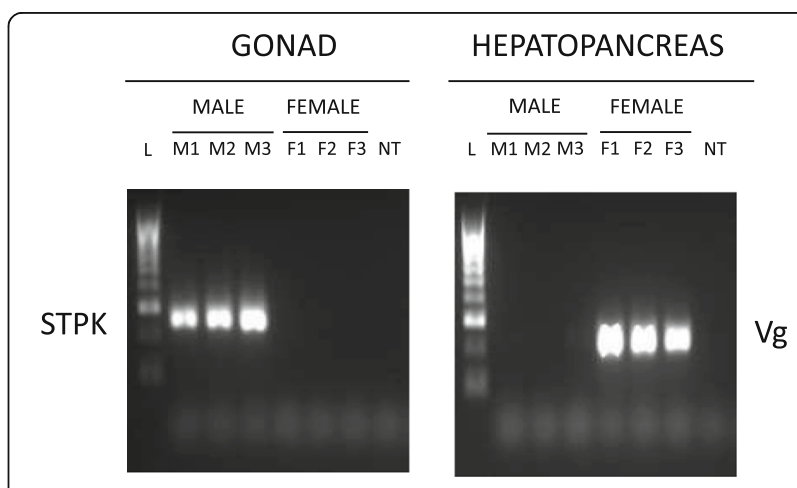

Fig. 4 Expression patterns of the highest sex-specific genes 


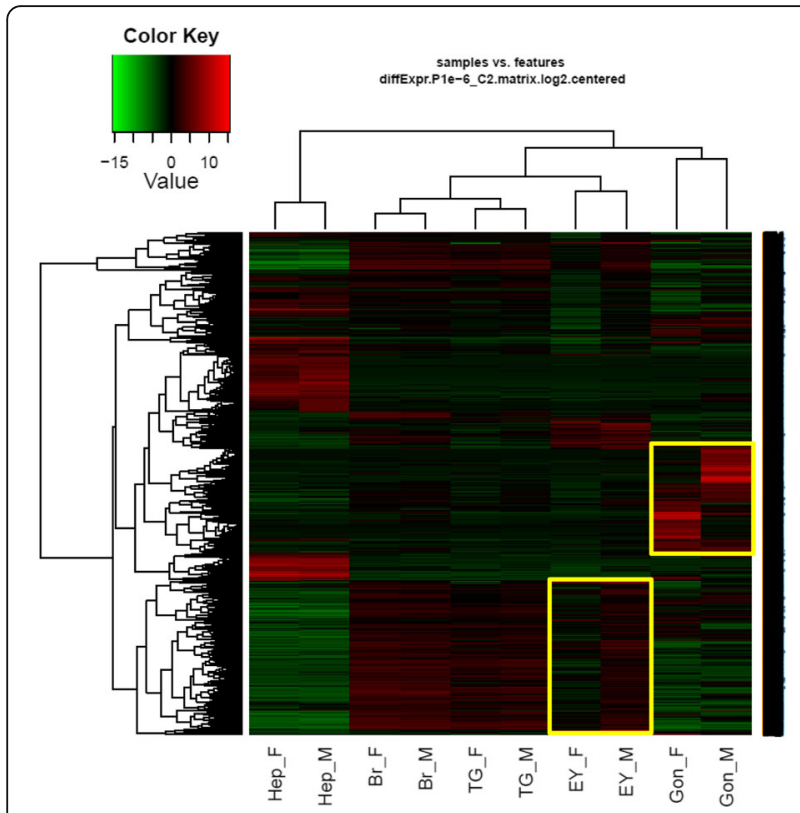

Fig. 5 Heatmap of differentially expressed genes between sexes. Yellow boxes represents cluster of genes that are highly differentiated between males and females

The Mitogen-activated protein kinase cascade is also involved in numerous male reproductive processes in mammals, including spermatogenesis, sperm maturation and activation, capacitation and acrosome reaction prior to fertilization of the oocyte [52]. Recently, cDNAs of cJun N-terminal MAPKs in E. sinensis showed relatively high expression in the testis and their expression were found to decrease gradually over time during spermatogenesis [53]. MAPK- extracellular signal-regulated kinase 2 element has also been identified in the green mud crab (Scylla paramamosain) and the giant tiger shrimp ( $P$. monodon), but in contrast in these species it has been implicated as playing a crucial role in ovary development $[54,55]$. Based on the transcription pattern specifically expressed in $N$. norvegicus testis, we suspect that the MAPK transcript in the present study, may be related to the c-Jun N-terminal kinases subfamily as reported for E. sinensis. In earlier studies, Laufer and Biggers [56] suggested a possible role for insect juvenile hormone and/or methyl farnesoate in activation of MAPK during reproduction and morphogenesis. Both studies implicate involvement of MAPK pathways during crustacean reproduction.

C-type lectins are a family of calcium-dependent carbohydrate-binding proteins that are believed to play important roles in innate immunity in crustaceans [57, 58]. In mammalian reproductive physiology, CTLs are involved in molecular mechanisms that underlie successful fertilization of embryos, a process via which sperm lectins recognize specific carbohydrates present on glycoproteins on the egg surface [59]. C-type lectins that mediate sperm-egg recognition and fusion during fertilization have also been detected in sperm and soluble extracts from adult males, but not females in the hookworm Ancylostoma ceylanicum [60]. Meprins are unique proteases in the astacin family of metalloendopeptidases, and indeed more widely across the animal kingdom. They have an oligomeric structure and are disulfide-linked dimers that are highly glycosylated. Meprins have many attributes of receptors or integrins with adhesion, epidermal growth factor-like and transmembrane domains [61]. Meprins represent excellent models of hetero- and homo-oligomeric enzymes that are regulated at the transcriptional and posttranslational levels. The crayfish enzyme, Astacin, was the first Meprin characterized and is one of the smallest members of the family [62]. Astacin metalloprotease has been identified in male ticks Dermacentor variabilis as enzymes important in seminal fluid and are considered to be necessary for processing of male accessory gland proteins following insemination of the female [63]. Following evidence from insects, we suggest that CTLs may potentially play a role in sperm-egg recognition in N. norvegicus while Meprins could be related to mating activity.

The Slowpoke locus encodes a calcium-activated potassium channel in animals. In Drosophila, this ion channel can mediate courtship behavior (males vibrate their wings to produce a 'song' that attracts females), influencing individual reproductive success [64]. In mammals, SLO is localized in the sperm flagellum and during fertilization this channel increases sperm intracellular calcium levels and membrane hyperpolarization [65]. We found SLO in N. norvegicus to be expressed exclusively in the testis. To our knowledge, this is the first record of exclusive expression of SLO in a single sex in a decapod crustacean. SLO has only recently been identified as a differentially expressed gene in both abdominal and cardiac nervous system tissues but not in gonads (gonads were not tested in the cited study) in American lobster $H$. americanus [29].

As for transcripts exclusively expressed in female $N$. norvegicus, RT-PCR results showed that Vitellogenin mRNA can be detected only in the hepatopancreas of females. This pattern is similar to that found in the freshwater edible crab Oziothelphusa senex where $\mathrm{Vg}$ can also only be found in the hepatopancreas but not in other tissues including eyestalk, Y-organ, mandibular organ, thoracic ganglion, hypodermis or ovary [66]. This suggests that $\mathrm{Vg}$ expression is sex-specific during secondary vitellogenesis when large amounts of yolk are required over a short period of time to provide exogenous reserves in mature oocytes. Vitellogenin receptor and Von Willebrand factor are also related to Vg. Vitellogenin is taken into developing oocytes from the hemolymph by VgR via receptor-mediated endocytosis [67]. Vitellogenin receptor was expressed in the ovary but 
not in testis in both P. monodon juveniles and adult and expression levels in ovaries were significantly higher in adults compared with juveniles. This gene is also upregulated during the final stage of ovarian development in adults [68]. Expression levels of genes with roles in ovarian development were not different between wild and domesticated $P$. monodon females, suggesting that $\mathrm{Vg}$ and $\mathrm{VgR}$ expression level is not related to broodstock condition and both influence maturation [69]. The D domain of mammalian VWF contains a similar sequence to that present in a freshwater crayfish Pacifastacus leniusculus. VWF is a clotting protein in the hepatopancreas and its sequence is homologous with $\mathrm{Vg}$ [70]. During maturation, oocytes consist mainly of yolk of which, the primary components are lipids. Lipid and lipoprotein oxidation have been documented using model systems containing purified myeloperoxidase in humans [71]. Presence of Myeloperoxidase in $\mathrm{H}$. americanus hemocytes was reported by Anderson and Beaven [72]. Myeloperoxidase is a heme-containing protein present in the hemocyte that converts hydrogen peroxide into hypochlorous acid. This reaction could be related to the ability of activated cells to produce antimicrobial reactive oxygen species.

In all Pleocyemate decapods, including $N$. norvegicus, the female just after laying her eggs, kneads them with her ovigerous setae. Pleocyemate decapods are known to contain high levels of $\mathrm{N}$-glycosylation sites on the proteoglycans associated with egg brooding. In blue swimmer crab Portunus pelagicus, Mannose-binding protein has been implicated in glycosylation [73]. Importance of glycosylation by MBP lies in a putative role in folding, processing and transport of this protein to the egg yolk as has been observed in $M$. rosenbergii [74].

A number of earlier studies have highlighted certain sexspecific transcripts including Ovarian serine protease/nudel homolog [32], Female sterile and Ovarian lipoprotein receptor [33], Double-sex mab-3 related transcription factor [34] and Nit protein 2-like and CYP3A4 [35]. In N. norvegicus, these genes were not identified as sex exclusive transcripts applying the designated threshold employed here. We did however, identify ovary-biased expression of ovarian serine protease/nudel homolog, female sterile and lipoprotein receptor. In addition, one DM-domain containing protein was predominantly expressed in the testis (Additional file 6: Table S4). It is also important to note that a relatively large number of sex-specific as well as sex-biased transcripts were detected in $N$. norvegicus and can be found in supplementary material (Additional file 3: Table S2 and Additional file 4: Table S3). Clustering of relative gene expression patterns using the heatmap approach illustrated that gonads and eyestalks were the tissues that showed the largest differences in sex-biased transcripts in $N$. norvegicus (Additional file 7: Figure S1). This is true despite the fact that Vitellogenin in the hepatopancreas was the most highly expressed transcript in females, but apart from $\mathrm{Vg}$, this tissue did not show a large number of transcripts differentially expressed between the sexes. Future investigations would therefore benefit from focusing mainly on transcripts differentially expressed in the gonad and eyestalk between sexes. These results also indicate that sex-specific gene regulatory pathways exist in somatic tissues in Norway lobster. Furthermore, observation that all validated genes were present in the genome of both sexes suggest that differences in gene expression between the sexes result from differences in gene regulation and not from effects of genes located on heterogametic sex chromosomes. This approach could serve as a template for future gene based studies related to sex differences in $N$. norvegicus.

\section{Conclusions}

- A reference transcriptome library was developed for $N$. norvegicus that has applications in future biological, wild restocking and fisheries studies.

- Sex-specific markers were mainly expressed in males in the 5 tissues tested implying that males may in general, experience stronger selection than females.

- Five sex-specific potential markers were identified in adult males (Serine threonine protein kinase, Venom c-type lectin, Mannose binding, Meprin and Slowpoke potassium channel protein) and females (Vitellogenin, Mannose-binding protein, Von Willebrand factor, Vitellogenin receptor and Meloxyperoxidase). All transcripts were sex-specific in the gonads except for Vitellogenin that was most highly expressed in the hepatopancreas.

- Differential expression among tissues revealed that tissues that possessed the largest numbers of sexbiased transcripts were the gonads and eyestalk with eyestalk showing higher expression levels in females.

- Sex-specific gene regulatory pathways exist in somatic tissues and not from effects of genes located on heterogametic sex chromosomes in the Norway lobster.

\section{Additional files}

Additional file 1: Table S1. RT-PCR primers for sex-specific transcripts and housekeeping genes. CTL: Venom c-type lectin mannose binding; EF 1-a: Elongation factor 1- a; GAPDH: Glyceraldehyde 3-phosphate dehydrogenase; MBP: Mannose-binding protein; MEP: Meprin; MAPK: Dual specificity mitogenactivated protein kinase; MPO: Meloxyperoxidase; SLO: Slowpoke potassium channel family; STPK: Serine threonine protein kinase; Vg: Vitellogenin, VgR: Vitellogenin receptor; WF: Von Willebrand factor. (DOCX 15 kb)

Additional file 2: Table S2. Full list of sex-specific transcripts. (XLSX $1280 \mathrm{~kb}$ )

Additional file 3: Figure S2. Gel results of validated sex-specific transcripts. (PDF 506 kb) 
Additional file 4: Table S3. Full list of differentially expressed transcripts between sexes. (XLSX $853 \mathrm{~kb}$ )

Additional file 5: Figure S3. PCA of sex-biased genes. (PDF 8 kb) Additional file 6: Table S4. List of differentially expressed transcripts between sexes reported in other studies identified in N. norvegicus. (XLSX 11 kb)

Additional file 7: Figure S1. Species distribution of blast hits. (DOCX $93 \mathrm{~kb}$ )

\section{Abbreviations}

AG: Androgenic gland; Bp: Base pairs; CEGMA: Core Eukaryotic Genes Mapping Approach; CTL: Venom c-type lectin mannose binding; CYP3A4: Cytochrome P450, family 3, subfamily A, polypeptide 4; DGE: Differential gene expression; Dmrt: Double-sex and mab-3 related transcription factor; EF1-a: Elongation factor 1 a; FAO: Food and Agriculture Organization; FDR: false discovery rate; FEM-1: Feminizer-1;

GAPDH: Glyceraldehyde 3-phosphate dehydrogenase; GIH/NIH: gonad/ vitellogenesis inhibiting hormone; GO: Gene Ontology; IAG: Androgenic gland insulin-like hormone; ICES: International Council for the Exploration of the Sea; MAPK: Dual specificity mitogen-activated protein kinase; MBP: Mannose-binding protein; MEP: Meprin; MF: methyl farnesoate; $\mathrm{MIH}$ : molt-inhibiting hormone; MPO: Meloxyperoxidase; NCBI: National Center for Biotechnology Information; NGST: next-generation sequencing technology; NIT2: Nit protein 2-like; nr: Non-redundant; PE: Paired-end; PMTST1: P. monodon testis-specific transcript 1; RT: Reverse Transcriptase; SLO: Slowpoke potassium channel family; STPK: Serine threonine protein kinase; SxI: Sex-determinant; TG: Thoracic ganglia; TRA 1: Transformer 1; TRA2: Transformer 2; Vg: Vitellogenin; VgR: Vitellogenin receptor; WWF: Von Willebrand factor; WEGO: Web Gene Ontology; XO-SG: X-organ-Sinus-gland complex

\section{Acknowledgements}

The current study was supported by a Marie Curie International Research Staff Exchange Scheme Fellowship within the 7th European Community Framework Programme (612296-DeNuGReC). The authors are grateful for the support of the crew of the fishing vessel Maireta for field sampling. All laboratory analyses were conducted in the Molecular Genetics Research Facility (MGRF) as part of Central Analytical Research Facility (CARF) Genomics at QUT. We would also like to acknowledge QUT HPC for computational support during the current study and Daniel Powell for providing Additional file 5: Fig. S3. We are also grateful to the unknown reviewers for their comments that had help to improve the quality of the MS.

\section{Funding}

The current study was supported by a Marie Curie International Research Staff Exchange Scheme Fellowship within the 7th European Community Framework Program (612296-DeNuGReC). Funding for lab work at QUT was provided by the Institute for Future Environments (IFE).

\section{Availability of data and materials}

The CSIC coordinate the European Project PIRSES-GA-2013-612,296 entitled "Development of genomic tools for assessing nutrition, growth and reproduction issues in farmed crustacean species (DeNuGReC)" that will end on the 31st October 2017. Researchers in CSIC are obligated to keep the transcriptomic data unpublished until all milestones and deliverables of the project have been accomplished. Although the transcriptomic data are not available now, data in relation to sex-specific and sex-biased genes are available in the additional files as Additional file 3: Table S2 and Additional file 4: Table S3. Furthermore, specific data may be released upon request to the corresponding author prior to the official release date.

\section{Authors' contributions}

GR, TVN and PM conceived the study, participated in its design, coordination and drafted the manuscript. VS contributed to the sampling, dissection and provided an extra dataset for the current study. GR and TVN carried out RNA extraction, cDNA synthesis and additional bioinformatics downstream analysis. $\mathrm{DH}$ helped in the design of the study and LR performed part of the bioinformatics analysis. VC was involved in Sanger sequencing confirmation and laboratory assistance. KD was involved in the sequencing and validation of genes and helped draft the manuscript. TV carried out the analysis of data and critically revised the manuscript. JBC and JA participated in the design, coordination and assisted with the manuscript draft and provided funding. All authors read and approved of the final manuscript.

\section{Ethics approval}

Not applicable.

The MS does not have any relevant ethical implications in relation to animals per se, since the animals used in this project are decapod crustaceans. These invertebrates are not protected by the current EU Directive 6/609/EEC. All invertebrate experiments will be conducted under national and EU legislation (directive 86/609/EEC and European convention for the protection of animals used for experimental or other scientific purposes). The 3Rs (Replace, Reduce, Refine) rule has been applied.

\section{Consent for publication}

Not applicable.

\section{Competing interests}

The authors declare that they have no competing interests.

\section{Publisher's Note}

Springer Nature remains neutral with regard to jurisdictional claims in published maps and institutional affiliations.

\section{Author details}

${ }^{1}$ Institut de Ciències del Mar (CSIC), Passeig Marítim de la Barceloneta, 37-49, 08003 Barcelona, Spain. ${ }^{2}$ Faculty of Science, Health, Education and Engineering, GeneCology Research Centre, University of the Sunshine Coast, Sunshine Coast, QLD, Australia. ${ }^{3}$ Department of Biology and Ecology of Fishes, Leibniz-Institute of Freshwater Ecology and Inland Fisheries, Müggelseedamm, 310 Berlin, Germany. ${ }^{4}$ Earth, Environmental and Biological Sciences, Science and Engineering Faculty, Queensland University of Technology, 2 George St, Brisbane 4001, Australia.

Received: 13 December 2016 Accepted: 1 August 2017 Published online: 16 August 2017

\section{References}

1. FAO FishStat. Species Fact Sheets [http://www.fao.org/fishery/statistics/en]

2. FAO: State of world fisheries and aquaculture 2012. In. Edited by FAO. Rome; 2012: 209.

3. Ventura T, Manor R, Aflalo ED, Weil S, Khalaila I, Rosen O, Sagi A: Expression of an androgenic-gland-specific insulin-like peptide during the course of prawn sexual and morphotypic differentiation. ISRN Endocrinology 2011, vol. 2011:Article ID 476283.

4. Ventura T, Manor R, Aflalo ED, Weil S, Rosen O, Sagi A. Timing sexual differentiation: full functional sex reversal achieved through silencing of a single insulin-like gene in the prawn. Macrobrachium rosenbergii Biology of Reproduction. 2012;86(3):90. 91-96

5. Levy T, Rosen O, Eilam B, Azulay D, Aflalo ED, Manor R, Shechter A, Sagi A. A single injection of hypertrophied androgenic gland cells produces allfemale aquaculture. Mar Biotechnol. 2016;18(5):554-63.

6. Pandian TJ. Reproduction and development in Crustacea, vol. 1. Kochi, India: CRC Press; 2016.

7. Chandler JC, Aizen J, Fitzgibbon QP, Elizur A, Ventura T. Applying the power of transcriptomics: understanding male sexual development in decapod Crustacea. Integr Comp Biol. 2016;

8. Kopp A. Dmrt genes in the development and evolution of sexual dimorphism. Trends Genet. 2012;28(4):175-84.

9. Nagaraju GPC. Reproductive regulators in decapod crustaceans: an overview. J Exp Biol. 2011;214(1):3-16.

10. De Loof A. Ecdysteroids: the overlooked sex steroids of insects? Males: the black box. Insect Sci. 2006;13(5):325-38.

11. Farmer ASD. Synopsis of biological data Onthe Norway lobster Nephrops norvegicus. FAO Fish Synop. 1975;112:1-97.

12. Sardà F. A review (1967-1990) o some aspects of the life history of Nephrops norvegicus. ICES Mar Sci Symp. 1995;199:78-88.

13. Sardà F: Nephrops norvegicus comparative biology and fishery in the Mediterranean Sea, vol. 62; 1998.

14. Johnson JL, Johnson MP. The ecology and biology of Nephrops norvegicus vol. 64. San Diego: Elsevier Academic Press Inc; 2013. 
15. Rotllant G, Chiva M, Durfort M, Ribes E. Internal anatomy and ultrastructure of the male reproductive system of the Norway lobster Nephrops norvegicus (Decapoda: Astacidea). J Morphol. 2012;273(6):572-85.

16. Rotllant G, Ribes $\mathrm{E}$, Company JB, Durfort M. The ovarian maturation cycle of the Norway lobster Nephrops norvegicus (Linnaeus, 1758) (Crustacea, Decapoda) from the western Mediterranean Sea. Invertebrate Reproduction \& Development. 2005;48(1-3):161-9.

17. Theissinger K, Falckenhayn C, Blande D, Toljamo A, Gutekunst J, Makkonen J. De novo assembly and annotation of the freshwater crayfish Astacus astacus transcriptome. Mar Genomics. 2016;28:7-10.

18. Ali MY, Pavasovic A, Amin S, Mather PB, Prentis PJ. Comparative analysis of gill transcriptomes of two freshwater crayfish, Cherax cainii and C-destructor. Mar Genomics. 2015;22:11-3.

19. Glazer L, Tom M, Weil S, Roth Z, Khalaila I, Mittelman B, Sagi A. Hemocyanin with phenoloxidase activity in the chitin matrix of the crayfish gastrolith. J Exp Biol. 2013;216(10):1898

20. Tom M, Manfrin C, Chung SJ, Sagi A, Gerdol M, De Moro G, Pallavicini A, Giulianini PG. Expression of cytoskeletal and molt-related genes is temporally scheduled in the hypodermis of the crayfish Procambarus clarkii during premolt. J Exp Biol. 2014;217(23):4193-202.

21. Tan MH, Gan HM, Gan HY, Lee YP, Croft LJ, Schultz MB, Miller AD, Austin CM. First comprehensive multi-tissue transcriptome of Cherax quadricarinatus (Decapoda: Parastacidae) reveals unexpected diversity of endogenous cellulase. Org Divers Evol. 2016;16(1):185-200.

22. Manfrin C, Tom M, De Moro G, Gerdol M, Guarnaccia C, Mosco A, Pallavicini A, Giulianini PG. Application of D-crustacean hyperglycemic hormone induces peptidases transcription and suppresses glycolysis-related transcripts in the Hepatopancreas of the crayfish Pontastacus leptodactylus — results of a transcriptomic study. PLoS One. 2013;8(6):e65176.

23. Ou J, Li Y, Ding Z, Xiu Y, Wu T, Du J, Li W, Zhu H, Ren Q, Gu W, et al. Transcriptome-wide identification and characterization of the Procambarus clarkii microRNAs potentially related to immunity against Spiroplasma eriocheiris infection. Fish Shellfish Immun. 2013;35(2):607-17.

24. Jiang HC, Xing ZJ, Lu W, Qian ZJ, Yu HW, Li JL. Transcriptome analysis of red swamp crawfish Procambarus clarkii reveals genes involved in gonadal development. PLoS One. 2014;9(8):9.

25. Shen H, Hu Y, Ma Y, Zhou X, Xu Z, Shui Y, Li C, Xu P, Sun X. In-depth transcriptome analysis of the red swamp crayfish Procambarus clarkii. PLoS One. 2014;9(10):e110548.

26. Piazza F, Aquiloni L, Peruzza L, Manfrin C, Simi S, Marson L, Edomi P, Giulianin PG: Managing of Procambarus clarkii by $X$-ray sterilisation of males: Cytological damage to gonads. Micron (Oxford, England : 1993) 2015, 77:32-40.

27. Bauer M, Greenwood SJ, Clark KF, Jackman P, Fairchild W. Analysis of gene expression in Homarus americanus larvae exposed to sublethal concentrations of endosulfan during metamorphosis. Comp BiochemPhysiol D. 2013;8(4):300-8

28. Clark KF, Acorn AR, Greenwood SJ. A transcriptomic analysis of American lobster (Homarus americanus) immune response during infection with the bumper car parasite Anophryoides haemophila. Developmental \& Comparative Immunology. 2013;40(2):112-22.

29. McGrath LL, Vollmer SV, Kaluziak ST, Ayers J. De novo transcriptome assembly for the lobster Homarus americanus and characterization of differential gene expression across nervous system tissues. BMC Genomics. 2016;17

30. Northcutt AJ, Lett KM, Garcia VB, Diester CM, Lane BJ, Marder E, Schulz DJ. Deep sequencing of transcriptomes from the nervous systems of two decapod crustaceans to characterize genes important for neural circuit function and modulation. BMC Genomics. 2016;17(1):868.

31. Sbragaglia V, Lamanna F, M Mat A, Rotllant G, Joly S, Ketmaier V, de la Iglesia HO, Aguzzi J. Identification, Characterization, and Diel Pattern of Expression of Canonical Clock Genes in Nephrops norvegicus (Crustacea: Decapoda) Eyestalk. PLoS ONE. 2015;10(11):e0141893.

32. Callaghan T, Degnan B, Sellars M. Expression of sex and reproduction-related genes in Marsupenaeus japonicus. Mar Biotechnol. 2010;12(6):664-77.

33. Preechaphol R, Leelatanawit R, Sittikankeaw K, Klinbunga S, Khamnamtong B, Puanglarp N, Menasveta P. Expressed sequence tag analysis for identification and characterization of sex-related genes in the giant tiger shrimp Penaeus monodon. J Biochem Mol Biol. 2007:40(4):501-10.

34. Zhang E-F, Qiu G-F. A novel Dmrt gene is specifically expressed in the testis of Chinese mitten crab. Eriocheir sinensis Development Genes and Evolution. 2010;220(5-6):151-9.
35. Liu Y, Hui M, Cui ZX, Luo DL, Song CW, Li YD, Liu L. Comparative Transcriptome Analysis Reveals Sex-Biased Gene Expression in Juvenile Chinese Mitten Crab Eriocheir sinensis. PLoS One. 2015;10(7)

36. Gao J, Wang X, Zou Z, Jia X, Wang Y, Zhang Z. Transcriptome analysis of the differences in gene expression between testis and ovary in green mud crab (Scylla paramamosain). BMC Genomics. 2014;15(1):585.

37. FastQC software [http://www.bioinformatics.babraham.ac.uk/projects/fastqc].

38. Bolger AM, Lohse M, Usadel B. Trimmomatic: a flexible trimmer for Illumina sequence data. Bioinformatics. 2014;30(15):2114-20.

39. Grabherr MG, Haas BJ, Yassour M, Levin JZ, Thompson DA, Amit I, Adiconis $X$, Fan L, Raychowdhury R, Zeng QD, et al. Full-length transcriptome assembly from RNA-Seq data without a reference genome. Nat Biotechnol. 2011;29(7):644-U130.

40. Parra G, Bradnam K, Korf I. CEGMA: a pipeline to accurately annotate core genes in eukaryotic genomes. Bioinformatics. 2007;23(9):1061-7.

41. Conesa A, Gotz S, Garcia-Gomez JM, Terol J, Talon M, Robles M. Blast2GO: a universal tool for annotation, visualization and analysis in functional genomics research. Bioinformatics. 2005;21(18):3674-6.

42. Ye J, Fang L, Zheng HK, Zhang Y, Chen J, Zhang ZJ, Wang J, Li ST, Li RQ Bolund L, et al. WEGO: a web tool for plotting GO annotations. Nucleic Acids Res. 2006;34:W293-7.

43. Langmead B, Trapnell C, Pop M, Salzberg SL. Ultrafast and memory-efficient alignment of short DNA sequences to the human genome. Genome Biol. 2009;10(3):R25-R25.

44. Li B, Dewey CN. RSEM: accurate transcript quantification from RNA-Seq data with or without a reference genome. Bmc Bioinformatics. 2011;12:16.

45. Robinson MD, McCarthy DJ, Smyth GK. edgeR: a Bioconductor package for differential expression analysis of digital gene expression data. Bioinformatics. 2010;26(1):139-40.

46. Leelatanawit R, Klanchui A, Uawisetwathana U, Karoonuthaisiri N. Validation of reference genes for real-time PCR of reproductive system in the black Tiger shrimp. PLoS One. 2012;7(12):e52677.

47. Zhou K, Wang M, Sun S. Effects of elevated temperature and food supply on the termination of over-summering and subsequent development of the Calanoid copepod Calanus sinicus: morphology Physiology and Gene Expression. PLoS ONE. 2016;11(9):e0161838.

48. Untergasser A, Cutcutache I, Koressaar T, Ye J, Faircloth BC, Remm M, Rozen SG. Primer3 - new capabilities and interfaces. Nucleic Acids Res. 2012;40(15):e115.

49. Chandler JC, Aizen J, Elizur A, Battaglene SC, Ventura T. Male sexual development and the androgenic gland: novel insights through the de novo assembled transcriptome of the eastern spiny lobster. Sagmariasus verreauxi Sexual Development. 2015;9(6):338-54.

50. He L, Wang $Q$, Jin XK, Wang $Y$, Chen LL, Liu LH, Wang Y. Transcriptome Profiling of Testis during Sexual Maturation Stages in Eriocheir sinensis Using Illumina Sequencing. PLoS One. 2012;7(3)

51. Phoungpetchara I, Tinikul Y, Poljaroen J, Changklungmoa N, Siangcham T, Sroyraya M, Chotwiwatthanakun C, Vanichviriyakit R, Hanna PJ, Sobhon P. Expression of the male reproduction-related gene (mar-Mrr) in the spermatic duct of the giant freshwater prawn. Macrobrachium rosenbergii Cell Tissue Res. 2012;348(3):609-23.

52. Li MWM, Mruk DD, Cheng CY. Mitogen-activated protein kinases in male reproductive function. Trends Mol Med. 2009;15(4):159-68.

53. Yang H, Li Q, Yu A, He L, Wang Q, Molecular characterization and subcellular distribution of JNK and JIP4 protein kinases in spermatogenesis and acrosome reaction of the Chinese mitten crab Eriocheir sinensis $\mathrm{H}$. Milne Edwards. Crustacea: Brachyura: Varunidae. J Crustacean Biol 2016. 1853;36(5):684-94

54. Ma A, Wang Y, Zou Z, Fu M, Lin P, Zhang Z. Erk2 in ovarian development of green mud crab Scylla paramamosain. DNA Cell Biol. 2012;31(7):1233-44.

55. Ponza P, Yocawibun P, Sittikankaew K, Hiransuchalert R, Yamano K, Klinbunga S. Molecular cloning and expression analysis of the mitogenactivating Protein kinase 1 (MAPK1) gene and protein during ovarian development of the Giant Tiger shrimp Penaeus monodon. Mol Reprod Dev. 2011;78(5):347-60

56. Laufer $\mathrm{H}$, Biggers WJ. Unifying concepts learned from methyl farnesoate for invertebrate reproduction and post-embryonic development. Am Zool. 2001:41(3):442-57

57. Xiu Y, Hou L, Liu X, Wang Y, Gu W, Meng Q, Wang W. Isolation and characterization of two novel C-type lectins from the oriental river prawn. Macrobrachium nipponense Fish Shellfish Immun. 2015;46(2):603-11. 
58. Huang Y, Huang X, Hou L, An L, Hui K-M, Ren Q, Wang W: Molecular cloning and characterization of three novel Hemocyanins from Chinese mitten crab, Eriocheir sinensis Aquaculture 2014, 434(0):385-396.

59. Rodeheffer C, Shur BD. Characterization of a novel ZP3-independent spermbinding ligand that facilitates sperm adhesion to the egg coat. Development. 2004;131(3):503-12.

60. Brown AC, Harrison LM, Kapulkin W, Jones BF, Sinha A, Savage A, Villalon N, Cappello M. Molecular cloning and characterization of a C-type lectin from Ancylostoma ceylanicum: evidence for a role in hookworm reproductive physiology. Mol Biochem Parasitol. 2007;151(2):141-7.

61. Bond JS, Beynon RJ. The astacin family of metalloendopeptidases. Protein Sci. 1995;4(7):1247-61.

62. Mohrlen F, Baus S, Gruber A, Rackwitz HR, Schnolzer M, Vogt G, Zwilling R. Activation of pro-astacin - immunological and model peptide studies on the processing of immature astacin, a zinc-endopeptidase from the crayfish Astacus astacus. Eur J Biochem. 2001;268(9):2540-6.

63. Sonenshine DE, Bissinger BW, Egekwu N, Donohue KV, Khalil SM, Roe RM. First Transcriptome of the Testis-Vas Deferens-Male Accessory Gland and Proteome of the Spermatophore from Dermacentor variabilis (Acari: Ixodidae). PLoS One. 2011:6(9).

64. Ding $Y$, Berrocal A, Morita T, Longden KD, Stern DL: Natural courtship song variation caused by an intronic retroelement in an ion channel gene. Nature 2016, 536(7616):329-+.

65. Mannowetz N, Naidoo NM, Choo S-AS, Smith JF, Lishko PV. Slo1 is the principal potassium channel of human spermatozoa. elife. 2013;2:e01009.

66. Girish BP, Swetha CH, Reddy PS. Hepatopancreas but not ovary is the site of vitellogenin synthesis in female fresh water crab, Oziothelphusa senex senex. Biochem Biophys Res Commun. 2014;447(2):323-7.

67. Subramoniam T. Mechanisms and control of vitellogenesis in crustaceans. Fish Sci. 2011;77(1):1-21.

68. Klinbunga S, Sittikankaew K, Jantee N, Prakopphet S, Janpoom S, Hiransuchalert R, Menasveta P, Khamnamtong B: Expression levels of vitellogenin receptor (Vtgr) during ovarian development and association between its single nucleotide polymorphisms (SNPS) and reproductionrelated parameters of the giant tiger shrimp Penaeus monodon. Aquaculture 2015, 435(0):18-27.

69. Rotllant G, Wade NM, Arnold SJ, Coman GJ, Preston NP, Glencross BD. Identification of genes involved in reproduction and lipid pathway metabolism in wild and domesticated shrimps. Mar Genomics. 2015;22:55-61.

70. Hall M, Wang R, van Antwerpen R, Sottrup-Jensen L, Söderhäll K. The crayfish plasma clotting protein: a vitellogenin-related protein responsible for clot formation in crustacean blood. Proc Natl Acad Sci. 1999;96(5):1965-70.

71. Kettle AJ, Winterbourn CC. Myeloperoxidase: a key regulator of neutrophil oxidant production. Redox Rep. 1997;3(1):3-15.

72. Anderson RS, Beaven AE. In vitro activation of hemocytes from the American lobster, Homarus americanus, as measured by production of reactive oxygen species. J Shellfish Res. 2005;24(3):699-703.

73. Kuballa AV, Elizur A. Differential expression profiling of components associated with exoskeletal hardening in crustaceans. BMC Genomics. 2008:9:14.

74. Roth Z, Parnes S, Wiel S, Sagi A, Zmora N, Chung JS, Khalaila I. N-glycan moieties of the crustacean egg yolk protein and their glycosylation sites. Glycoconj J. 2010;27(1):159-69.

\section{Submit your next manuscript to BioMed Central and we will help you at every step:}

- We accept pre-submission inquiries

- Our selector tool helps you to find the most relevant journal

- We provide round the clock customer support

- Convenient online submission

- Thorough peer review

- Inclusion in PubMed and all major indexing services

- Maximum visibility for your research

Submit your manuscript at www.biomedcentral.com/submit 